University for Business and Technology in Kosovo

UBT Knowledge Center

UBT International Conference

2018 UBT International Conference

Oct 27th, 1:30 PM - 3:00 PM

\title{
Small-scale physical modelling of slope failures in sands
}

M. Tasevska

SS. Cyril and Methodius University, m.tasevska123@gmail.com

B. Susinov

SS. Cyril and Methodius University, susinov@gf.ukim.edu.mk

J. Josifovski

SS. Cyril and Methodius University, jjosifovski@gf.ukim.edu.mk

Follow this and additional works at: https://knowledgecenter.ubt-uni.net/conference

Part of the Civil and Environmental Engineering Commons

\section{Recommended Citation}

Tasevska, M.; Susinov, B.; and Josifovski, J., "Small-scale physical modelling of slope failures in sands" (2018). UBT International Conference. 71.

https://knowledgecenter.ubt-uni.net/conference/2018/all-events/71

This Event is brought to you for free and open access by the Publication and Journals at UBT Knowledge Center. It has been accepted for inclusion in UBT International Conference by an authorized administrator of UBT Knowledge Center. For more information, please contact knowledge.center@ubt-uni.net. 


\title{
Small-scale physical and numerical modelling of slope failure in sand
}

\author{
Tasevska M. ${ }^{1}$, Susinov B. ${ }^{2}$, Josifovski J. ${ }^{3}$ \\ ${ }^{1}$ „Ss. Cyril and Methodius“ University, Faculty of Civil Engineering - Skopje, R. \\ Macedonia \\ ${ }^{2}$,Ss. Cyril and Methodius“ University, Faculty of Civil Engineering - Skopje, R. \\ Macedonia \\ 3 „Ss. Cyril and Methodius“ University, Faculty of Civil Engineering - Skopje, R. \\ Macedonia \\ m.tasevska123@gmail.com, susinov@gf.ukim.edu.mk, \\ jjosifovski@gf.ukim.edu.mk
}

\begin{abstract}
The paper presents a small-scale physical and numerical modeling of slope stability. The aim is to define the critical angle at which slope failure occurs. The slope material used is uniform sandy material used in Topolnica tailing dam construction. An extensive laboratory tests have been made to determine the physical and mechanical properties of the soil. In this study two physical experiments were performed, in addition to which also two numerical models, Finite element method and Limit equilibrium method, were calculated. The first experimental model refers to slope angle of 45 degrees with increasing load on the top is simulating an upslope extension until the failure occurs. The second experimental model has a different mechanism which instead of changing load a raising upward motion is used to increase the slope angle until failure. The results show that the first slope fails when $13 \mathrm{kPa}$ external load was applied. In the second case the failure occurs at slope angle of 62 degrees. A shallow slope failure occurs in both cases. Finally, the experimental results are validated with two numerical models, the first one presenting a safety factor while the other a stress-deformation distribution. The results from the physical and numerical modeling are in perfect agreement
\end{abstract}

Keywords: Small-scale physical modeling, Numerical modeling, Slope stability, Critical slope angle.

\section{Introduction}

The slope stability depends on numerous factors, such as the lithological and morphological conditions, mechanical properties etc. Another very important indicator of instability could be the climatic perturbations especially the rainfall [1]. The listed factors in combination usually influence together the slope instability [2].

The investigation is organized and performed in three phases. In the first phase the material properties were determined through laboratory tests. The second phase is the physical modeling, when two different small-scale experiments were executed. In the last phase two numerical calculations were performed and compared with those from the experiments. 


\section{Physical modeling}

\section{Material characterization}

The slope material is characterized as silty sand uniform fine sand which is a byproduct of the copper and flotation mine near Radovis, Macedonia. This material is used for the construction of the Topolnica tailing dam. The testing samples are taken from four boreholes located over the entire surface of the dam. An appropriate classification tests were carried out to define the mechanical properties and deformation characteristics of the material.

According the obtained results, the following values can be adopted for further analysis:

- Specific gravity $G s=2.72$

- Dry bulk density $\gamma_{d}=15.5 \mathrm{kN} / \mathrm{m}^{3}$

- Optimum humidity $\omega=22.5 \%$

- Internal friction angle $\varphi=33^{\circ}$

- Cohesion $c=0 \mathrm{kPa}$

- Compressibility modulus $M v$ 25-800 kPa $=1459.3-16814.7 \mathrm{kPa}$

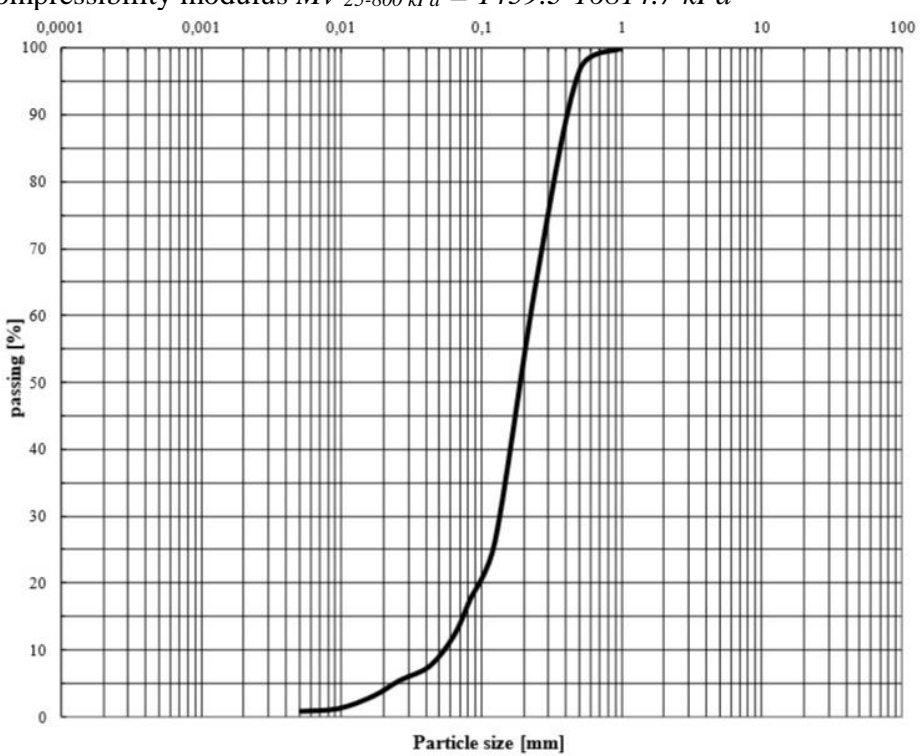

Fig. 1. Granulometric curve

The sieve analysis produced a granulometric curve of the material which is shown in Figure 1. The material contains $82.5 \%$ sand and $17.5 \%$ silt that classifies it as fine silty sand. The coefficient of uniformity is $C u=4.29$ and the curvature coefficient is $C c=1.51$ [3].

\section{Model description}

In the first phase of this study, a simplified physical model was developed for determination of the critical slope angle with different moisture percentage of the material.

A physical model with dimensions as shown in Figure 2a) (given in $\mathrm{cm}$ ) was build. A material with $3 \%$ of water content was placed into a box without compaction. The experiment was performed by gradually lifting the box on one side causing the angle of the slope gradually 
increasing (Figure 2b). The change in the slope angle has generated a shallow slip surface which progressed very fast until a sudden failure occurred.

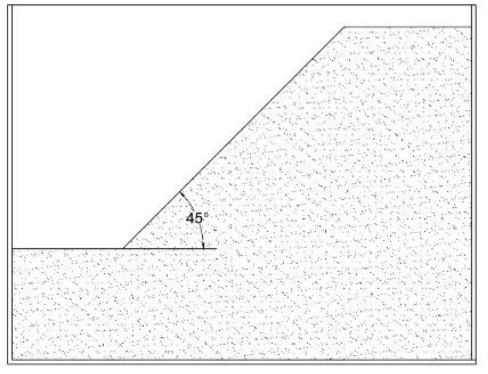

a)

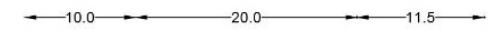

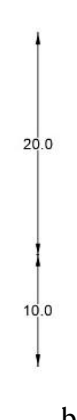

b)

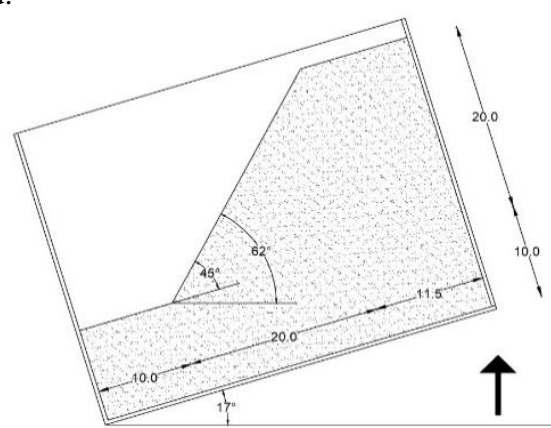

ined physical model No.1

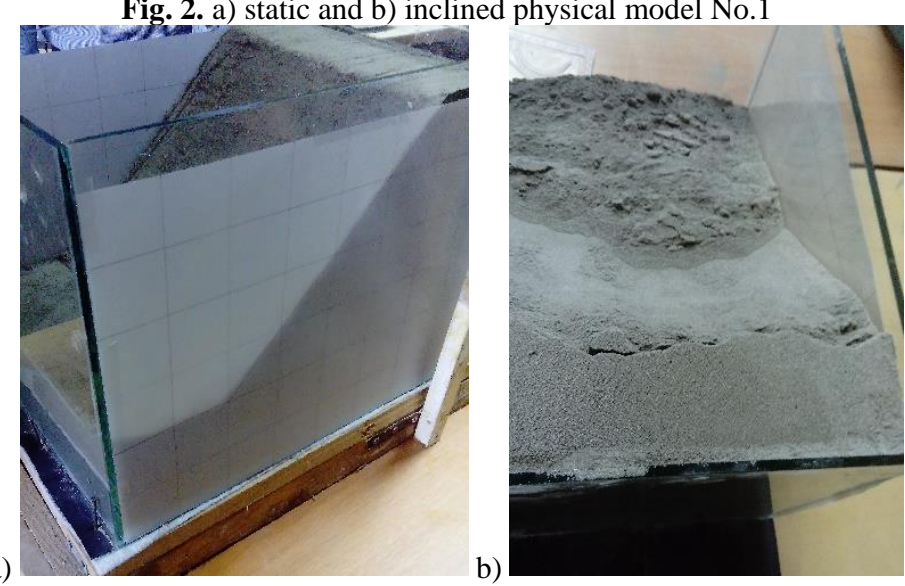

Fig. 3. Photos of the model a) before the test and b) after the test

Three models with different water content all smaller than the optimal were modeled:

- dry material with moisture of $0 \%$

- assumed natural moisture of $3 \%$, and

- $8.5 \%$ which is twice lower than the optimum moisture

The experiment on physical model No.1 was performed for loose and compacted dry material. The first one is without compacting which is unstable at slope angle of 40 degrees which is due to the looseness of the material. The second model differs in the density of the material, i.e. this time it is evenly compacted in layers at a height of $5 \mathrm{~cm}$, which does not determine any significant difference from the first experiment thus it can be concluded that the critical angle of the modeled slope is 40 degrees.

The experiment on physical model No.2 is considered a slope with moisture content of $3 \%$ and angle variation increasing evenly at each cycle. The first crack was registered at slope angle of 57 degrees. For slope angle of 60 degrees some contours already start to appear. A shallow failure occurred for a slope angle of 62 degrees.

The next experiment was carried out for material water content of $8.5 \%$. The behavior of the slope in this case was different due to the fact that the material was well compact. In the next step, a physical model No.1 as in Figure 1 (a) with a moisture of $3 \%$ was build. In this case, the slope remained constant $\left(45^{\circ}\right)$ while the height of the slope was increased by applying a uniformly distributed load at the top of the slope (Figure 4). 

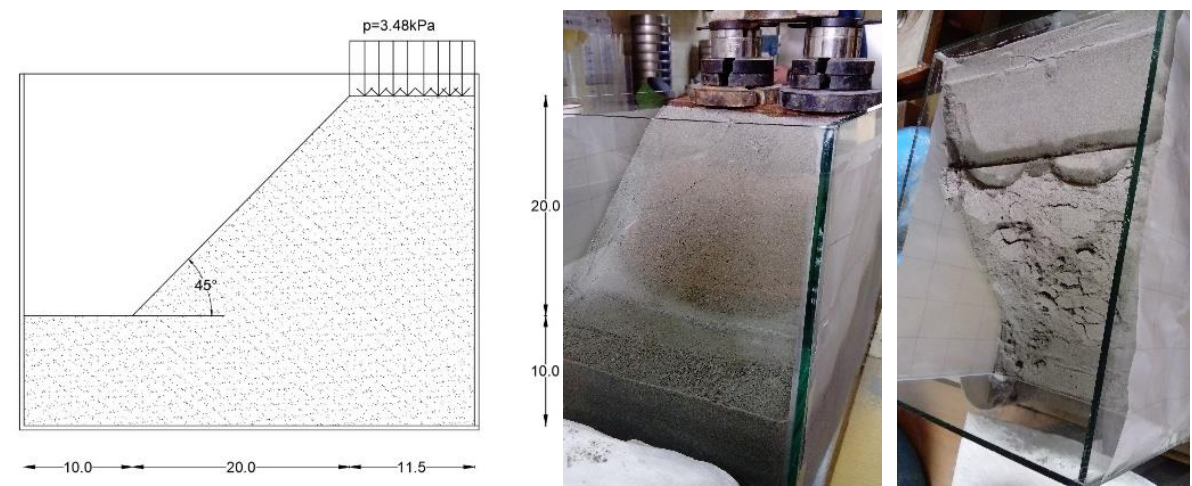

Figure 4. Physical model No.2 a) a sketch and b) photos from before and after the test

The load increased until the moment when the mass sliding occurred. Each subsequent loading step was smaller than the previous in order to gradually monitor the development of the slope deformations. The slope behaves quite stable until the load of $6.5 \mathrm{~kg}$ without no cracks on the slope. It is noted that the density of the material is dependent on the moisture. In this case the additional loading of the slope only speeds up the consolidation process causing a saving of the slope instead of the slope instability.

\section{Numerical modeling}

After the experiments a numerical two-dimensional analysis was performed with software Slide. The goal was to confirm the critical slope angle for each experiment, compare the sliding surfaces and determine the safety factor. Hence, a plane strain two-dimensional analysis was performed with third dimension equal to the unity, thus the width of the physical model being $0.27 \mathrm{~m}$ (different from the unity) has to be corrected in the results obtained in Slide. The ratio is needed to determine the critical uniformly distributed load. The correction is given by simple proportion of dimensions, i.e. for the physical model:

- $\quad$ Width of the slope $\mathrm{B}=0.27 \mathrm{~m}$

- Area of loading $\mathrm{A}=0.0182 \mathrm{~m}^{2}$

- $\quad$ Distributed load $\mathrm{P}=3.48 \mathrm{kPa}$

In the numerical model width and the area of loading is different, so it follows:

- Width of the slope $B_{1}=1 \mathrm{~m}$

- Area of loading $\mathrm{A}_{1}=0.07 \mathrm{~m}^{2}$

According to the dimensions of the physical model and those of the numerical one a correction of the applied load is made:

$$
\mathrm{N}_{1}=\left(\mathrm{N} * \mathrm{P}_{1}\right) / \mathrm{P} \Rightarrow \mathrm{N}_{1}=13.4 \mathrm{kPa}
$$

The results obtained from the numerical analysis of this method, in the case of a critical without additional load $\left(\alpha=62^{\circ}\right)$ and a critical axis with additional load $\left(\alpha=45^{\circ}\right.$ and $\left.\mathrm{N}=13.5 \mathrm{kPa}\right)$ are given in Figures 4 and 5. 


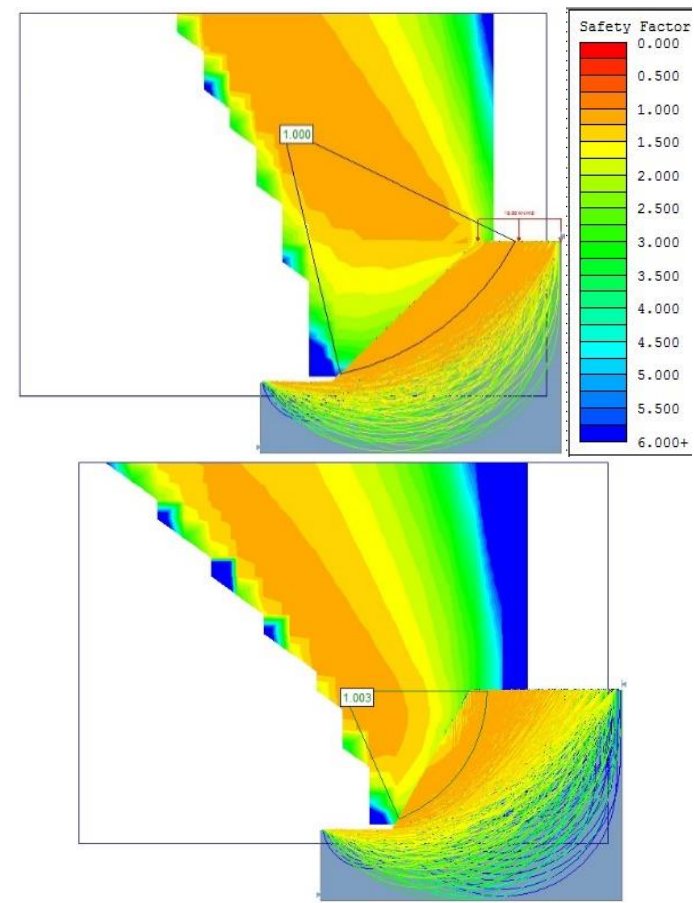

Fig. 4. Critical sliding plane a) slope angle of $45^{\circ}$ and b) slope angle of $62^{\circ}$

\section{Back analysis}

The last step was back analysis performed in the software Slide. With this analysis we can determine cohesion and internal friction angle for factor of safety equal to 1 .

The analysis was done for the slope of $45^{\circ}$ with additional load of $13.5 \mathrm{kN}$ and without it. The results are given on the diagrams below.

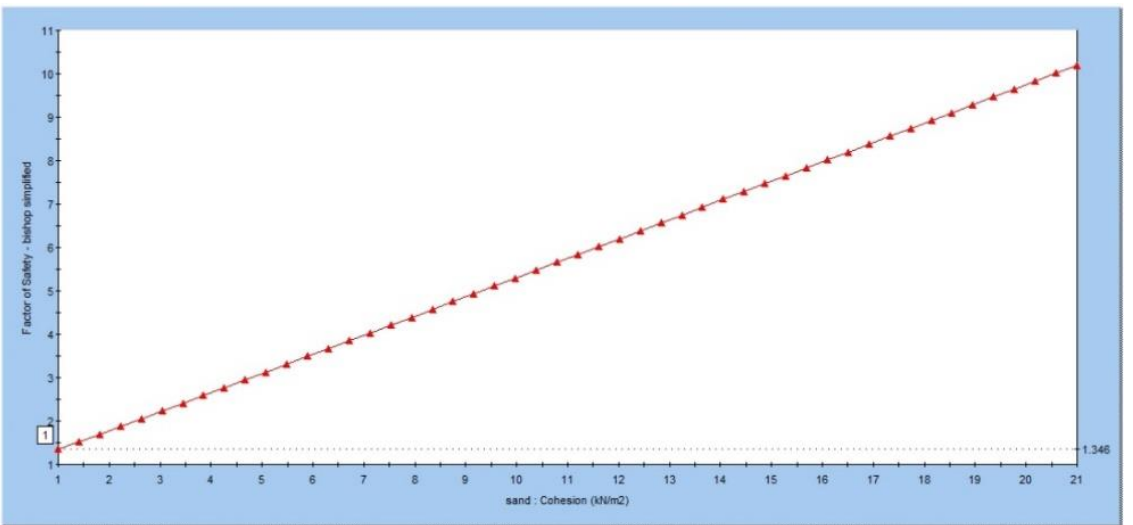

Fig. 5. Correlation between cohesion and factor of safety for the slope without additional loads 


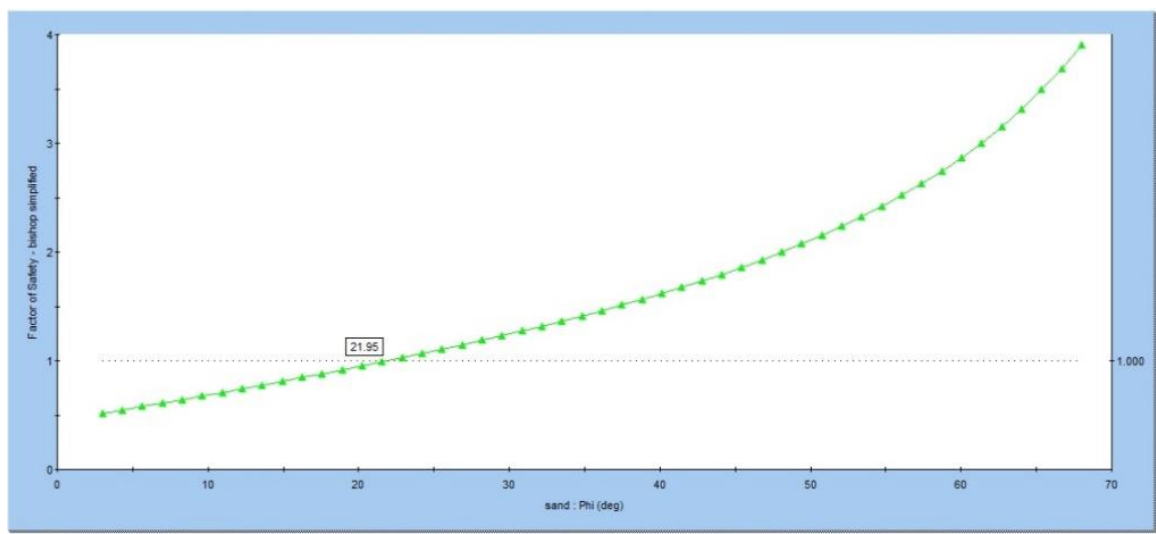

Fig. 6. Correlation between internal friction angle and factor of safety for the slope without additional loads

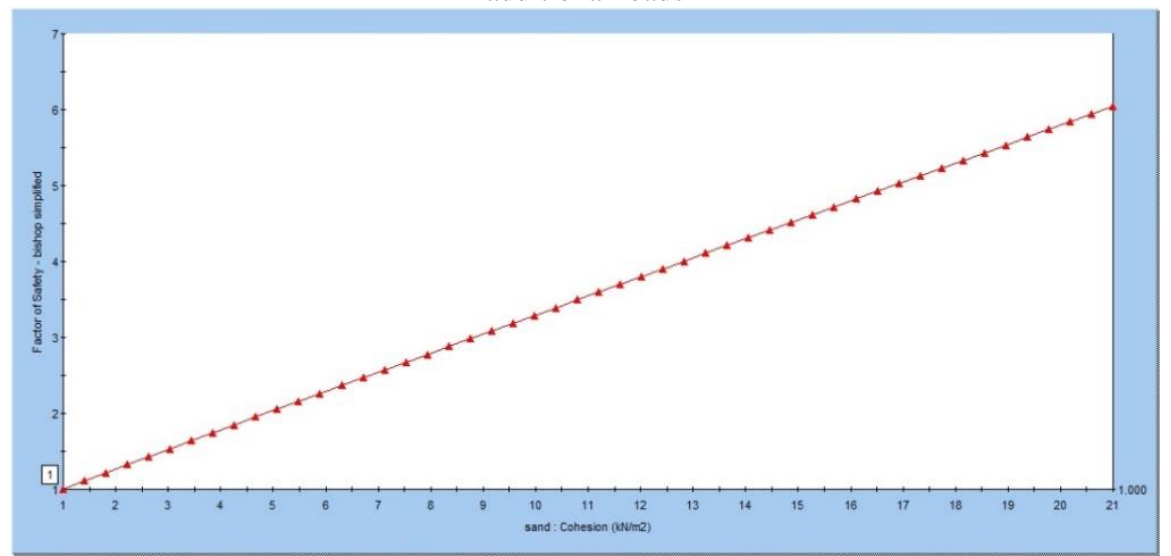

Fig. 7. Correlation between cohesion and factor of safety for the slope with additional loads

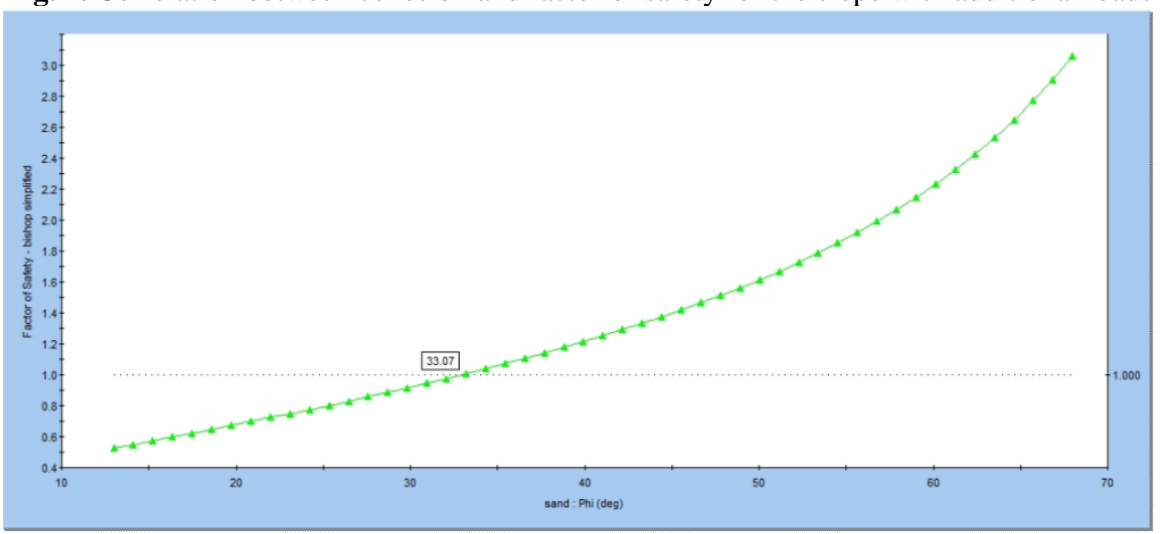

Fig. 8. Correlation between internal friction angle and factor of safety for the slope with additional loads 


\section{Conclusions}

In this paper three experiments have been performed to determine the critical slope angle of uniform fine sand. From the investigation it was concluded that the water content of the material influences the results. For a moisture of $3 \%$ the critical angle of the slope with additional load is $45^{\circ}$, while for a slope without additional load, the critical angle of the slope is $62^{\circ}$.

Later on these two models were calculated in a numerical analysis using the software Slide. The analysis has confirmed the results, the critical slope angle, obtained on the physical supporting them by an adequate factor of safety. For the model without additional load the results are the same as obtained with physical modeling, i.e. for the slope angle of $62^{\circ}, \mathrm{FS}=1,003$. For the model with additional load this analyze also gives the same results as the physical analyze. To define the load that would be equal to that added to a physical model, simple proportion was done, and with that results numerical analyze was made. In this case, for the additional load of $13.4 \mathrm{kPa}$ and the slope angle $45^{\circ}, \mathrm{FS}=1.0$.

After the numerical modelling, back analysis was made to determine internal friction angle and cohesion of the material for $\mathrm{FS}=1$. In the case, for additional load of $13.4 \mathrm{kPa}$ and the slope angle $45^{\circ}, \mathrm{c}=1 \mathrm{kPa}$ and $\varphi=33^{\circ}$, and in the case of the slope angle $45^{\circ}$ without additional load, $\mathrm{c}=0.7 \mathrm{kPa}$ and $\varphi=22^{\circ}$.

Moreover, it these points, it can be considered that the moisture of the material is very important, but it is the other topic that is planned for some other investigations in the future.

Finally, it was concluded that a very important factor in modeling is scale effect, and it is suspected that because of the small dimensions of the physical model, the critical slope angle without additional load on the slope is $62^{\circ}$, which is very steep inclination. This inclination was difficult to be built in real proportions and is rare case in the nature, especially for fine sand material.

\section{References}

1. Jovanovski, M. (2012), Soil mechanics, Faculty of Civil Engineering, Skopje

2. Maksimovic, M. M. (2008), Soil mechanics, AGM knjiga doo, Zemun

3. Susinov, B. \& Josifovski, J. (2018) Investigation of the hydro-mechanical properties of silty sand material from Topolnica tailings dam, XVI Danube - European Conference on Geotechnical Engineering, Skopje, R. Macedonia

4. Hakro, M. R. and Harahap, I. S. H. (2015) Laboratory experiments on rainfall-induced flowslide, NHESSD 3 (2015), p. 1575-1613

5. Josifovski, J. \& Lenart, S. (2016) Some experience in numerical modeling of unsaturated slope instabilities

6. Josifovski, J., Susinov, B. \& Lenart, S. (2017) Unsaturated analyzes of extreme rainfall influence on the landslide stability, WMHE 2017 15th International Symposium on Water Management and Hydraulic Engineering

7. Susinov, B. \& Josifovski, J. (2018) Investigation of the hydro-mechanical properties of silty sand material from Topolnica tailings dam 